\title{
Investigação geofísica em bota-fora de estéril afetada por processo de drenagem ácida na mina Osamu Utsumi - Poços de Caldas - MG
}

Matheus Felipe Stanfoca Casagrande, César Augusto Moreira*, Renata Augusta Sampaio Paes. Universidade Estadual Paulista "Júlio de Mesquita Filho", Programa de Pós Graduação em Geociências e Meio Ambiente, IGCE, campus Rio Claro (SP)

\section{Copyright 2018, SBGf - Sociedade Brasileira de Geofísica}

Este texto foi preparado para a apresentação no VIII Simpósio Brasileiro de Geofísica, Salinópolis, 18 a 20 de setembro de 2018. Seu conteúdo foi revisado pelo Comitê Técnico do VIII SimBGf, mas não necessariamente representa a opinião da SBGf ou de seus associados. É proibida a reprodução total ou parcial deste material para propósitos comerciais sem prévia autorização da SBGf.

\section{Resumo}

A drenagem ácida de mina é um problema pertinente na indústria mineradora e seus efeitos são observados na mina de urânio Osamu Utsumi, operada pelas Indústrias Nucleares do Brasil - INB. Foram aplicados os métodos geoelétricos da Eletrorressitividade (EM) e Polarização Induzida (PI) com 0 intuito de se avaliar o fluxo subterrâneo local e a delimitação de áreas de interação dessas águas com zonas ricas em pirita presentes em blocos rochosos dispostos em um bota-fora de estéril. Os resultados preliminares apontam para a existência de anomalias de baixa resistividade ( $<70$ Ohm.m) nas seções geofísicas, provavelmente em decorrência da elevada salinidade ocasionada pelos processos de drenagem ácida. Porções de elevada resistividade e cargabilidade, por outro lado, podem ser entendidas como sulfetos disseminados inseridos em redes venulares de quartzo, prováveis zonas de reação. Um fluxo preferencial de direção NW foi observado através do centro do bota-fora, condicionada pela topografia original do terreno onde foi instalada a BF-04.

\section{Introdução}

Com a evolução e diversificação dos processos tecnológicos, as fontes de contaminação mais comuns da água subterrânea são tidas por lixões e aterros mal operados; efluentes e resíduos de atividades industriais; vazamentos em postos de combustível e oleodutos; acidentes viários e ferroviários; vazamento de redes coletoras de esgoto; uso incorreto de insumos agrícolas; atividades mineradoras; dentre outras, onde o potencial de poluição do sistema hídrico é diretamente relacionado às características, quantidade e forma de lançamento do poluente e da vulnerabilidade intrínseca do aquífero (CETESB 2016; CORSEUIL e MARINS, 1997).

No caso da indústria mineradora, é amplamente conhecido seu potencial negativo ao meio ambiente, sobretudo no que se diz respeito à disposição dos estéreis e rejeitos provenientes da exploração e processamento dos bens minerais. Minas de urânio, sejam elas a céu aberto ou subterrâneas, são ainda mais problemáticas do ponto de vista ambiental devido à significativa gama de possibilidades de contaminação do meio físico, que abrangem desde a poluição das águas subterrâneas e superficiais locais por metais pesados e radionuclídeos como também a contaminação atmosférica por poeira e ${ }^{222} \mathrm{Rn}$ gerados pelas atividades de operação. Fernandes et al. (1998) ressalta a importância do projeto de lavra e o volume de minério explorado na extensão dos potenciais impactos associados e lista os seguintes conhecimentos básicos na análise dos impactos ambientais causados por tais poluentes: quantidade e composição do efluente emitido; evolução temporal do poluente; dispersão do material no meio; fatores para o cálculo da transferência dessas substâncias para espécies sensíveis; relação entre concentração de poluentes e as espécies afetadas e, por sua vez, a relação destas últimas com o custo ambiental.

Com a exposição de minerais sulfetados, outrora isolados do ar atmosférico em subsuperfície, e sua reação com oxigênio, produz efluentes de baixo $\mathrm{pH}$ e com concentrações elevadas de metais e metaloides, processo conhecido como drenagem ácida de mina (DAM) (AKCIL \& KOLDA, 2006). É neste contexto de contaminação que está inserida um bota-fora de estéreis (BF-4) da mina de urânio "Usamu Utsumi" pertencente ao Complexo Industrial de Poços de Caldas - CIPC (atualmente denominado de Unidade de Tratamento de Minério - UTM) operado pelas Indústrias Nucleares do Brasil - INB e que se encontra em atual processo de recuperação ambiental e descomissionamento. Dada a presença dessas águas ácidas e ricas em sais dissolvidos, métodos geofísicos são uma alternativa no diagnóstico de áreas contaminadas em razão da rapidez e baixo custo, auxiliando na detecção e monitoramento juntamente com métodos diretos de investigação, como poços de monitoramento (MOREIRA et al., 2006).

O objetivo do trabalho é a avaliação da resposta geoelétrica, através da técnica de tomografia elétrica na BF-4 afetada pelo processo de drenagem ácida. Com base nisso, será avaliado o fluxo subterrâneo local, gerado pela infiltração da água pluvias, e a delimitação de áreas de interação dessas águas com zonas ricas em pirita presentes em blocos rochosos dispostos no botafora de estéril, cujas reações são tidas como causa principal do processo de drenagem ácida de mina.

\section{Metodologia/ Problema Investigado}

Foram definidas 9 linhas de aquisição dispostas de tal maneira a cobrir toda a área do patamar inferior da BF4 (Fig. 1). O comprimento total das mesmas foi de 400 metros, com exceção da linha 5 cuja dimensão de 350 metros foi restringida por particularidades do terreno. Os 
eletrodos utilizados foram do tipo cerâmica nãopolarizável contendo solução de sulfato de cobre e a profundidade a partir da secção do modelo em diferentes níveis.

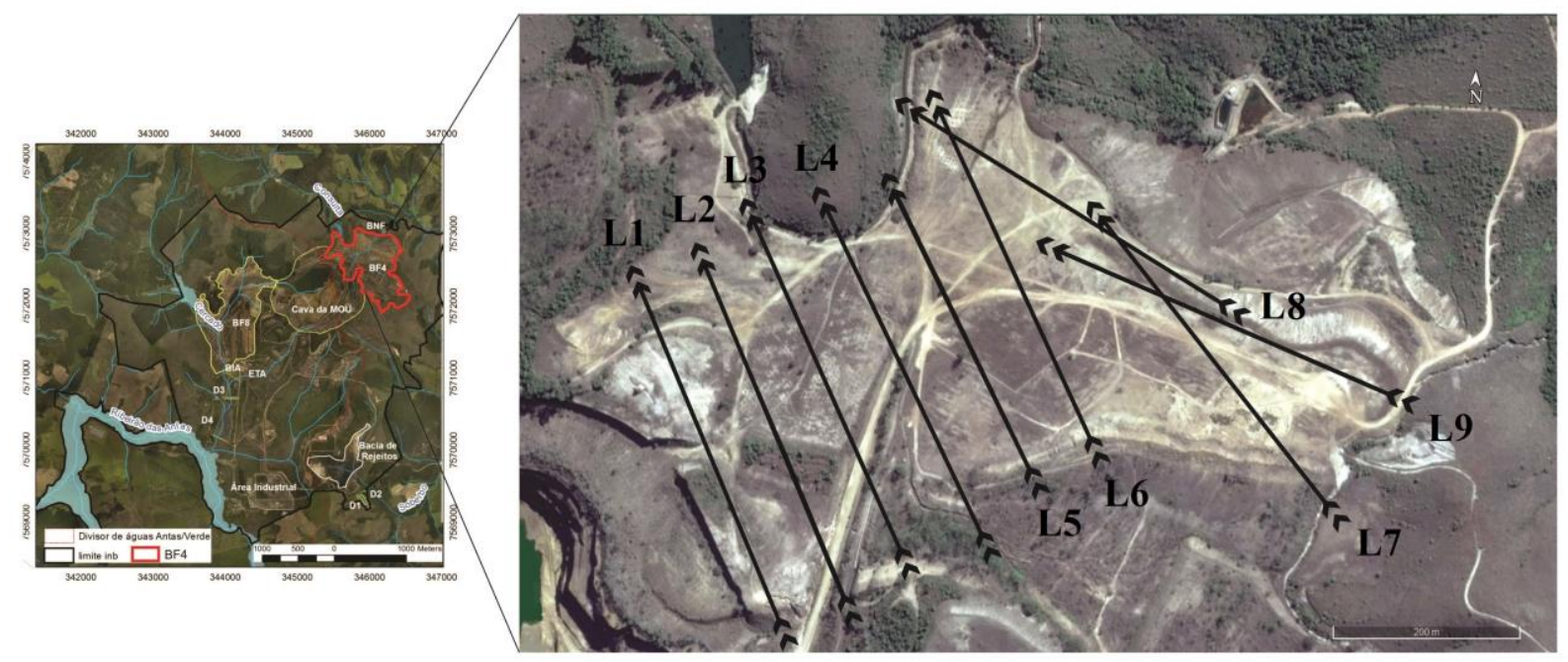

Figura 1 - Localização da área de estudo, com a delimitação da BF-04 dentro das instalações da INB .

distância estabelecida entre os mesmos foi de 10 metros. Os dados de pseudo-resistividade e cargabilidade referentes aos métodos da eletrorresistividade (RE) e polarização induzida (IP), respectivamente, foram obtidos por arranjo Schlumberger e a técnica escolhida foi o imageamento elétrico, propiciando uma visualização de anomalias dos parâmetros medidos em subsuperfície por meio de seções e modelos de visualização 3D. O equipamento utilizado em campo foi um resistivímetro Terrameter LS da ABEM de fabricação sueca.

Os dados adquiridos durante os trabalhos de campo foram processados pelo software Res2Dinv (2D) versão 3.53 (Geotomo Software) onde foram geradas suas representações por meio de imageamento elétrico dos valores quantitativos de resistividade e cargabilidade em subsuperfície. Os modelos de inversão são expressos em seções com base em suas variáveis distância e profundidade, além de apresentar seus valores convertidos em escala gráfica em razão logarítmica (MOREIRA et al., 2016).

As etapas para a obtenção dos modelos pseudo-3D da BF4 seguiram os mesmos princípios utilizados na área da prospecção mineral, com a utilização da plataforma Oasis Montaj (Geosoft), na qual os arquivos de planilhas foram carregados e os dados referentes às seções foram interpolados com base no método da krigagem para criação de modelos de blocos, seguido pela mínima curvatura para que fosse possível a suavização e elaboração de mapas multinível. Através disso, a malha amostral utilizada, juntamente com critérios estatísticos, estabelece diferentes blocos para cada ponto do modelo pseudo 3D final, possibilitando a geração de mapas de

\section{Resultados e discussões}

De acordo com os dados geofísicos processados e as seções de resistividade e cargabilidade geradas, foi possível a identificação de anomalias em subsuperfície associadas a fluxos preferenciais da água subterrânea na BF4, sobretudo porções de significativa baixa resistividade (menores que 70 Ohm.m) provavelmente em decorrência da elevada salinidade ocasionada pelos processos de drenagem ácida vigentes no local. Com base em interpretações conjuntas entre as seções de resistividade e cargabilidade, foi possível a identificação de potenciais processos-chave geradores da drenagem de mina ácida.

Abaixo foram selecionadas algumas das seções de resistividade e cargabilidade para a exemplificação e discussão desses processos químicos em detrimento ao modelo geofísico proposto. No caso da Linha 1 (Fig. 2), a uma distância aproximada de $310 \mathrm{~m}$ a partir da origem, observa-se de uma anomalia caracterizada por elevada resistividade (> 12000 Ohm.m) (Fig. 2a) e cargabilidade (> $10.1 \mathrm{mV} / \mathrm{V}$ ) (Fig. $2 \mathrm{~b}$ ), o que poderia ser entendida como sulfetos disseminados inseridos em redes venulares de quartzo, frutos da atividade hidrotermal na área. Associado a esta anomalia está uma porção de significativa baixa resistividade $(<70$ Ohm.m), tida como drenagem ácida resultado da interação água-minério. $O$ intervalo de resistividade para o aquífero não afetado pelo processo de contaminação seria de 75 - 209 Ohm.m, enquanto que valores de até 1583 Ohm.m, que abrangem uma grande porção da seção, corresponderiam ao embasamento rochoso significativamente fraturado, dada a pouca espessura do bota-fora no local de aquisição da Linha 1. Uma vez que 
a extremidade NW da linha de aquisição termina nas proximidades do um córrego, é possível que exista alguma contribuição desse corpo hídrico superficial na geração da referida anomalia de baixa resistividade, sobretudo através da infiltração dessas águas no sistema e a possível interação química com sulfetos representados pela zona de alta cargabilidade/resistividade, conforme já mencionado.

Um fenômeno análogo pode ser observado em outras seções geofísicas. No caso da Linha 2 há ainda uma grande zona de alta resistividade e cargabilidade no centro da seção que se prolonga a profundidades maiores (Fig. 3). A resistividade observada (> 4000 Ohm.m) certamente é referente ao embasamento rochoso maciço do bota-fora, ou seja, indicador da topografia original do terreno e condicionante da suspensão do lençol freático do aquífero granular gerado pela BF-04, evidenciado, por sua vez, pela anomalia superficial de baixa resistividade.

A análise dos dados do piezômetro 03 , com pH médio de 3,5 e condutividade da ordem $9853 \mu \mathrm{S} / \mathrm{cm}$ em medições realizadas de 2000 a 2005 (FRANKLIN, 2007), possibilitou a calibração do modelo geofísico proposto. $\mathrm{Na}$ Figura 4 é possível constatar que o piezômetro em questão se encontra instalado próximo a uma zona de baixa resistividade da Linha 3 , o que corroboraria a acidez e alta salinidade das águas coletadas nesse ponto. Ao utilizar dados de profundidade da base dos estéreis estéreis (ALBERTI, 2017), foi possível ainda a delimitação do contato da base da BF-04 com o topo rochoso, algo que seria próximo à topografia original do terreno pré-empreendimento (Fig. 4, linha pontilhada). É interessante observar a concentração das anomalias de baixa resistividade no interior da BF-04, principalmente na distância de 160 metros, onde parece haver um "acúmulo" ou caminho preferencial da água subterrânea (a ser confirmado com o modelo 3D) devido à concavidade da referida interface. As anomalias de cargabilidade, por sua vez, estão mais associadas com o corpo rochoso, onde foram obtidos valores superiores a $10.1 \mathrm{mV} / \mathrm{V}$ e que poderiam contribuir para a geração da drenagem de mina ácida e consequentemente formação das anomalias de baixa resistividade associadas. Dentro da BF-04 também se observam porções de cargabilidade da ordem de $6,5 \mathrm{mV} / \mathrm{V}$, provavelmente estéreis mais ricos em sulfetos e potenciais sítios de oxidação.

A interpolação das nove seções geofísicas levantadas geraram dois modelos pseudo-3D, um para cada parâmetro físico medido em campo. As imagens foram suavizadas e definidos nove níveis de visualização em profundidades correspondentes às cotas 1395 (superficial), 1383, 1371, 1359, 1347, 1335, 1323, 1311 e 1299 metros. Essa profundidade teórica de aquisição abrange as porções mais profundas do BF-04 de estéreis, cuja espessura máxima é em torno de 70 metros nas porções mais próximas ao talude (extremidade NE da Fig. 1) e diminui em direção a antiga cava da mina (extremidade SW da Fig. 1).

Com as seções interpoladas em modelos pseudo-3D foi possível a visualização das referidas anomalias tanto na extensão na área da BF-04 quanto no embasamento rochoso. As imagens da mostraram que as anomalias de alta resistividade e cargabilidade se tornam significativamente maiores em função da profundidade, o que seria de esperar, já que os níveis mais profundos representariam 0 terreno original de rochas menos alteradas (este último parâmetro ligado à presença de minerais sulfetados, por exemplo). As anomalias de baixa resistividade, já descritas anteriormente, formam um


Figura 2 - Modelos de inversão de resistividade (a) e cargabilidade (b) referentes a Linha 1. 
SE

NW

a) ${ }_{1396}^{\text {Elev }}$

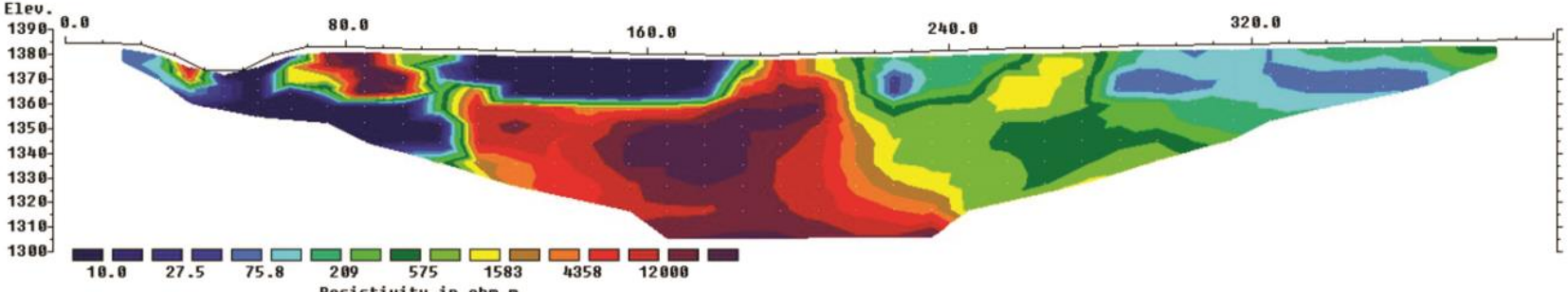

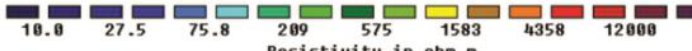
Resistivity in ohn.m

b)

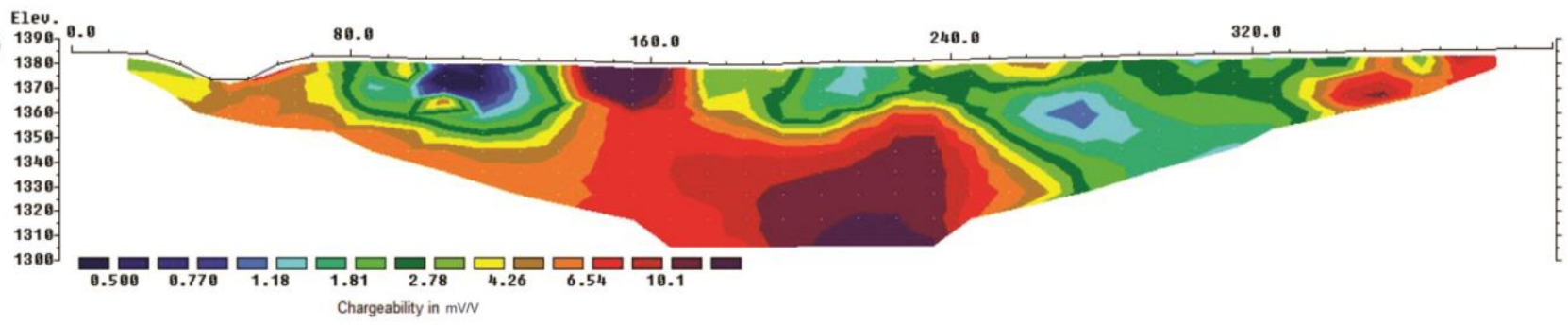

Figura 3 - Modelos de inversão de resistividade (a) e cargabilidade (b) referentes a Linha 2.

\section{SE}

a)

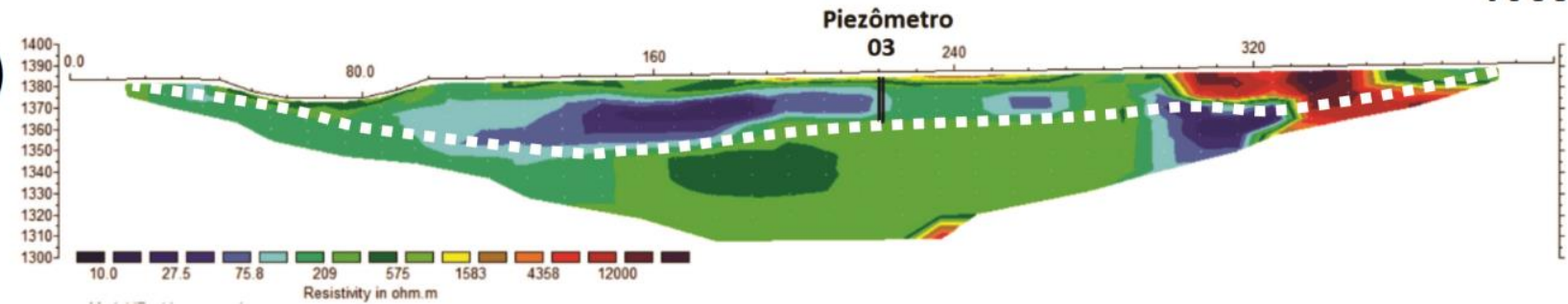

b)

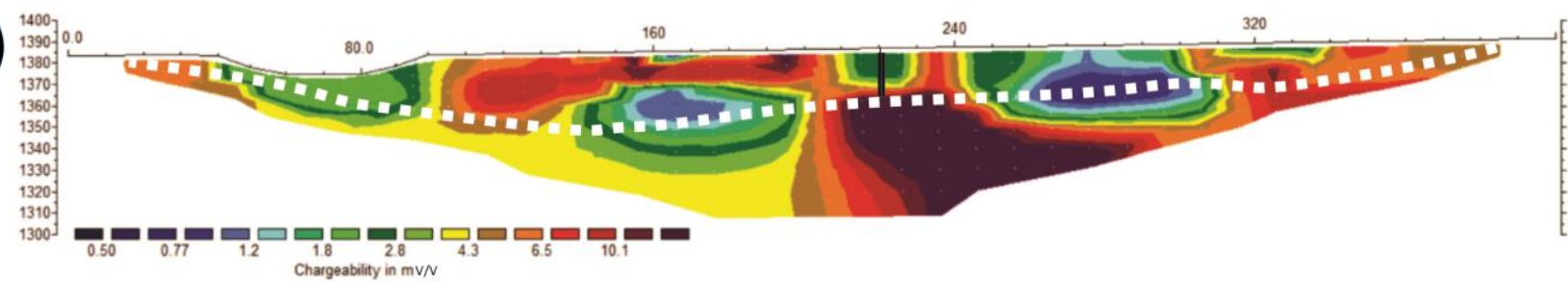

Figura 4 - Modelos de inversão de resistividade (a) e cargabilidade (b) referentes a Linha 3 com a delimitação do contato pilha de estéril-topo rochoso, segundo mapa de isópacas da BF04 (ALBERTI, 2017) e piezômetro 03 (FRANKLIN, 2007). 
prolongamento na área do bota-fora que pode ser visto principalmente nos dois primeiros níveis de visualização (1395 e 1371 metros). Essa característica poderia ser entendida como a superficialidade do lençol freático salino, se propagando na direção da bacia de captação na base BF-04 (extremidade NE). No que tange às anomalias de cargabilidade, existem várias porções superficiais da ordem de 6,5 a $10,1 \mathrm{mV} / \mathrm{V}$ que certamente alimentam o processo de drenagem de mina ácida, associadas a resquícios de rochas com sulfetos (pirita) em meio aos estéreis, conforme já mencionado.

Através dos modelos pseudo-3D foi possível a seleção de determinados valores dos parâmetros físicos medidos e sua visualização em imagens 3D de isovalores (Fig. 5). Elas representam superfícies de valores específicos, 10 ohm.m e $9 \mathrm{mV} / \mathrm{V}$ para resistividade e cargabilidade, respectivamente. É uma ferramenta interessante, pois possibilita a sobreposição dos dois parâmetros em uma única imagem, onde há a indicação de uma área específica caracterizada por baixa resistividade e alta cargabilidade (Fig. 5c), certamente uma porção importante na geração do processo de contaminação e de interesse em futuros projetos de mitigação.

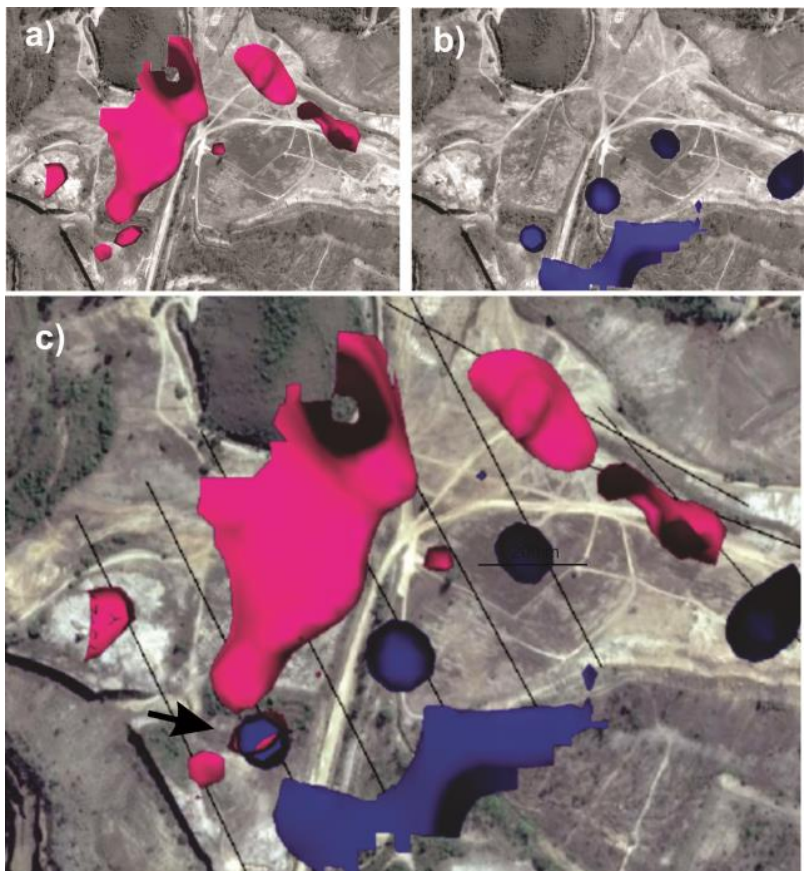

Figura 5 - Modelos preliminares pseudo-3D de isovalores. A cor rosa representa cargabilidade da ordem de $>9 \mathrm{mV} / \mathrm{V}$ e a azul valor de resistividade de $<10 \mathrm{ohm} . \mathrm{m}$. A terceira imagem (c) é a sobreposição de ambas (a e b), com a indicação de uma zona específica de alta cargabilidade e baixa resistividade (seta preta).

Ao comparar o sentido de fluxo proposto para as anomalias de baixa resistividade com o mapa de isópacas da BF-04 (Fig. 6), percebe-se uma clara relação entre ambas. A água subterrânea no BF-04 parece seguir a porção mais profunda do BF-04, o que na prática seria análogo a uma drenagem em vale fechado (topografia original do terreno). Esse fluxo seguiria em direção a NW e no sentido da bacia de captação, onde a profundidade do pacote de atinge seu valor máximo. As extremidades da BF-04, de menor espessura, apresentam altos valores de resistividade, que podem estar associadas a altas cargabilidade, justamente pela posição rasa das rochas do embasamento nas laterais do bota-fora.

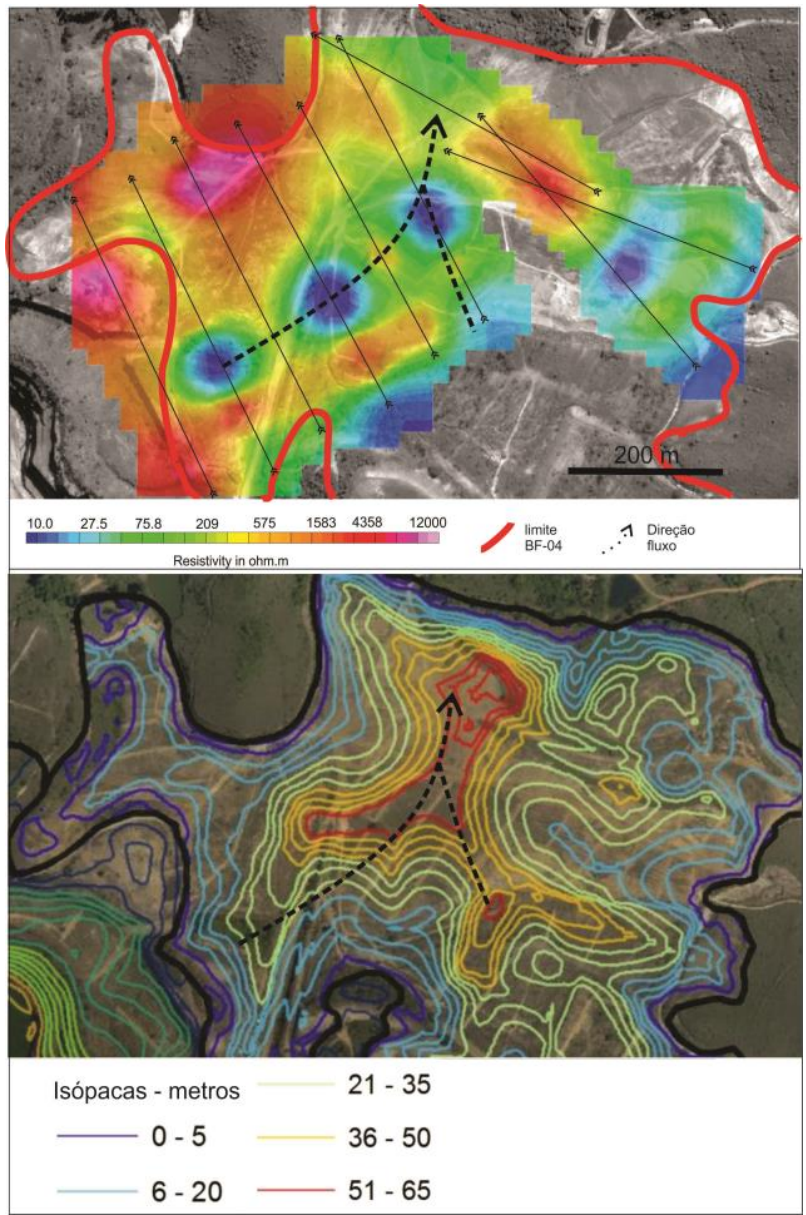

Figura 6- Comparação entre o fluxo preferencial gerado pelo método da eletrorresistividade com o mapa de isópacas da BF-04. Aparentemente o fluxo da água subterrânea se dá de SW para NE, mesma direção da porção alongada de maior profundidade do bota-fora (Mapa segundo (ALBERTI, 2017).

\section{Conclusões}

O conjunto de métodos propostos foi consistente no estudo da dinâmica da água subterrânea no sistema aquífero granular, sobretudo na identificação de padrões de fluxo no interior do bota-fora (<70 Ohm.m). Foram identificados processos-chave na geração do processo de drenagem ácida de mina, com anomalias de alta 
cargabilidade (> $9 \mathrm{mV} / \mathrm{V}$ ) relacionadas a sulfetos disseminados nas rochas do embasamento ou na próprio material estéril.

A água subterrânea no sistema aquífero granular seria alimentada pela infiltração da água pluvial e também provavelmente de um córrego próximo (conforme discutido na Linha 1), onde reagiria com os sulfetos disseminados e em sistemas venulares e geraria efluentes de alta salinidade e baixo $\mathrm{pH}$, detectados como anomalias de baixa resistividade. Essa água subterrânea seguiria na direção NW pelo centro do BF-04, condicionada pela topografia original do terreno onde foi instalada a BF-04. A indicação dessas zonas potenciais para a oxidação dos sulfetos propiciaria mais uma base para o estudo, planejamento e execução de medidas de recuperação da área.

Os dados geofísicos puderam ser correlacionados a dados diretos de piezômetros, análises químicas e mapas topográficos pré-empreendimento, 0 que corrobora ao modelo geofísico proposto, sobretudo na locação de mais poços de monitoramento a medidas

\section{Agradecimentos}

Ao Conselho Nacional de Desenvolvimento Científico e Tecnológico (CNPq).

\section{Referências}

Akcil, A., Koldas, S. 2006. Acid Mine Drainage (AMD): causes, treatment and case studies. Journal of Cleaner Production, vol. 14, 1139-1145.

Alberti, H. L. C. 2017. Estudo hidroquímico e isotópico das águas subterrâneas impactadas pela drenagem ácida da mina de urânio - Osamu Utsumi, Planalto de Poços de Caldas (MG). Dissertação de mestrado, Universidade Estadual de Campinas, Campinas, SP.

CETESB (COMPANHIA AMBIENTAL DO ESTADO DE SÃO PAULO). 2016. Poluição das águas subterrâneas. Disponível em: $<$ http://aguassubterraneas.cetesb.sp.gov.br/poluicao-dasaguas-subterraneas/>. Acesso em: 15 de Setembro de 2016.

Corseuil, H. X., Marins, M. M. 1997. Contaminação de águas subterrâneas por derramamento de gasolina: o problema é grave? Revista Engenharia Sanitária e Ambiental, Rio de Janeiro, vol.2, n.2, 50-54.

Fernandes, H. M., Franklin, M. R., Veiga, L. H. 1998. Acid rock dreinage and envionmental impacts. A study case of the Uranium mining and milling facilities at Poços de Caldas. Waste Management, vol. 18, 169-181.

FRANKLIN, M. R. 2007. Modelagem numérica do escoamento hidrológico e dos processos geoquímicos aplicados à previsão da drenagem ácida em uma pilha de estéril da mina de urânio de Poços de Caldas - MG. Tese de Doutorado, Universidade Federal do rio de Janeiro, RJ.

Moreira, C. A., Dourado, J. C., Braga, A. C. O. 2006. Aplicação da técnica de caminhamento elétrico em área contaminada por derivados de petróleo. Revista Brasileira de Geofísica, São Paulo, v. 24, n. 4, 1-10.

Moreira, C. A., Lapola, M. M., Carrara, A. 2016. Comparative analyzes among electrical resistivity tomography arrays in the characterization of flow structure in free aquifer. Geofísica Internacional, vol. 55, $2,119-129$. 